\title{
Epidemiology and Treatment for Thyroid Cancer
}

\author{
Srilatha $B^{1 *}$, Hima Bindu $A^{2}$ and Soumya $D^{3}$
}

${ }^{1}$ Department of Biotechnology, Presidency College, Bangalore University, India

${ }^{2}$ Department of Biotechnology, Andhra Vidyalaya P.G College, Osmania University, Hyderabad, India

${ }^{3}$ Department of Microbiology, Chaitanya Degree \& P.G College, Kakatiya University, Warangal, India

\begin{abstract}
The thyroid gland produces thyroid hormones which are important in the normal regulation of the metabolism of the body. Thyroid cancer is the most common malignancy of the endocrine system consisting of several subtypes like papillary carcinoma, and follicular carcinoma, medullary carcinoma, and anaplastic carcinoma. Treatment depends on a number of factors, including the type of thyroid cancer, the size of the nodule, the patient's age, and whether the cancer has spread. Most cases of thyroid cancer can be cured with treatment like Radiation therapy chemotherapy and radioactive iodine. Recommended thyroid treatment approaches depend on the type of thyroid disease, and in some cases, the severity of the condition.
\end{abstract}

Keywords: Thyroid gland; Thyroid cancer; Papillary carcinoma; Follicular carcinoma; Medullary carcinoma; Anaplastic carcinoma; Chemotherapy; radioactive iodine.

Abbreviations: (TSH): Human thyroid stimulating hormone; (SCH): Subclinical hypothyroidism; (Mets): Metabolic syndrome; (HSNCC): Head and neck squamous cell carcinoma; (PTC): Papillary thyroid cancer; (ATCs): Anaplastic thyroid carcinomas; (EGF): Epidermal growth factor; (RT): Radiotherapy; (RAI): Radioactive iodine;

\section{Introduction}

The thyroid gland is one of the largest endocrine glands. The nervous system, the endocrine, and the immune system are connected physiologically and act in a synchronized manner to mediate the body's quick and precise response to environmental stress [1].The thyroid gland is found in the neck, below to the thyroid cartilage the isthmus the bridge between the two lobes of the thyroid is located inferior to the cricoids cartilage. The thyroid gland controls how quickly the body uses energy, makes proteins and controls how sensitive the body is to other hormones and proteins for signal transduction; biosynthesis of secondary metabolites and those whose function were unknown were lowly expressed [2].It participates in these processes by producing thyroid hormones, the principal ones being triiodothyronine $\left(\mathrm{T}_{3}\right)$ and thyroxin $\left(\mathrm{T}_{4}\right)$. These hormones regulate the rate of metabolism and affect the growth and rate of function of many other systems in the body.

Human thyroid stimulating hormone (TSH) is a glycoprotein secreted by the anterior part of the pituitary gland. TSH plays an important physiological role in the regulating the hypothalamicpituitary-thyroid axis by modulating the release of the thyroid hormones from the thyroid gland. It induces iodine uptake by the thyroid, promotes thyroid epithelial differentiation and growth, and protects thyroid cells from apoptosis. Impairment of TSH signal transduction pathway leads to thyroid disorders such as goiter, hypothyroidism and hyperthyroidism, which can have complex clinical manifestation [3].

Hypothyroidism is a frequent complication in patients treated for head and neck cancer, with reported incidences as high as 52\% with multimodal therapy. Although hypothyroidism is a known risk factor for cardiovascular disease, there is no consensus regarding the impact of subclinical hypothyroidism (SCH) on metabolic syndrome (Mets) [4].
Thyroidism is one of the most important causes of preventable mental retardation, occurring in approximately 1 in 2000 to 4000 newborn infants. With the introduction of a screening program worldwide, it was observed that congenital hypothyroidism was associated with a higher frequency of extra-thyroidal congenital anomalies compared to the normal population [5]. Hypothyroidism is a frequent complication in patients treated for head and neck cancer, with reported incidences with multimodal therapy [6].

Thyroid cancer is a cancer that starts in the thyroid gland. Increasing cancer incidence is typically interpreted as an increase in the true occurrence of disease but may also reflect changing pathological criteria or increased diagnostic scrutiny. Changes in the diagnostic approach to thyroid nodules may have resulted in an increase in the apparent incidence of thyroid cancer [7]. Head and neck squamous cell carcinoma (HSNCC) is highly invasive, frequently metastasizing to cervical lymph nodes and corresponds with poor prognosis [8]. Tumor cell invasion and metastasis is a compounding problem in cancer management, with therapeutic intervention of tumor invasion becoming recognized as an increasingly relevant clinical factor. Increased activation of the proto-oncogene c-Src ( $\mathrm{Src}$ ) has been established in enhancing tumor progression in human cancer and corresponds with poor clinical outcome. Metastasis is the final stage of cancer and is still associated with high mortality despite breakthroughs in recent years [9].

\section{Types of Thyroid Cancer}

Current research on diseases of the ear, nose, throat and related structures of the head and neck has experienced significant strides in areas including cancer, otology, rhinology and laryngology. Molecular diagnostics and advanced imaging modalities including positron

*Corresponding author: Srilatha B, Presidency College, Bangalore University India, E-mail: srilatha.biotech09@gmail.com

Received November 03, 2011; Accepted December 14, 2011; Published December 16, 2011

Citation: Srilatha B, Hima Bindu A, Soumya D (2011) Epidemiology and Treatment for Thyroid Cancer. J Cancer Sci Ther S17. doi:10.4172/1948-5956.S17-011

Copyright: ( $\odot 2011$ Srilatha B, et al. This is an open-access article distributed under the terms of the Creative Commons Attribution License, which permits unrestricted use, distribution, and reproduction in any medium, provided the original author and source are credited. 
emission tomography have facilitated diagnosis and patient outcomes. Collaborations between physicians and laboratory researchers working to identify key clinical issues and translating the biological insights into novel therapeutic approaches are crucial to significant progress in the field [10].

Thyroid cancer constitutes a heterogeneous group of malignancies which exceeds half a million cases annually, ranking it as the fifth most common cancer worldwide [11].Head and neck cancers account for $6 \%$ of all cancers worldwide, with nearly 150,000 new cases in Europe alone each year. The distribution of primary tumor sites is: oral cavity (49\%), pharynx (23\%) and larynx (28\%). Patients with recurrent, metastatic disease have a poor prognosis, with a median survival of around 6-7 months in addition, patients failing first-line therapy have few therapeutic options [12].

\section{Papillary Thyroid cancer}

Papillary micro carcinomas are a specific subgroup of papillary thyroid cancer. They have the same histological features as papillary thyroid cancer but are $1.0 \mathrm{~cm}$ or less in diameter. These tumors are a common incidental finding at autopsy and in thyroid glands excised for other pathology. This tumor can metastasize to regional lymph nodes but its ability to cause significant morbidity and mortality has been questioned. As papillary micro-carcinomas can represent up to 30 per cent of all papillary cancers seen in a thyroid surgeon's practice, they are an important group [13].Lymphangiomas are diffusely infiltrating, benign vascular tumors that appear most commonly in the first 2 decades of life [14].

Papillary tumors of the thyroid are the most common form of thyroid cancer to result from exposure to radiation. Furthermore, clinical response by measurement of tumor size is often discordant with the pathological evaluation, such as the clinically response of approximately $70 \%$ in most studies, the partial or complete regression in histopathological biopsy analysis is less than 30\% [15]. However, in these studies, the diagnostic sensitivity was not sufficiently evaluated because of the small number of carcinoma [16].

PTC is common, although it rarely results in disease-specific mortality. It is being diagnosed increasingly in the subclinical phase as a result of enhanced ultrasound imaging and more aggressive surveillance of smaller thyroid nodules [17]. The purpose of this study was to review the histological features of proliferative nodules and to ascertain the utility of immune histochemistry and analyses of oncogenic mutations in signaling components of the MAP kinase pathway as diagnostic adjuncts [18] multispectral imaging platform is mainly for Tumor-associated change [19].

Papillary thyroid cancer (PTC), the most common thyroid malignancy, is associated with an excellent prognosis. Overall survival is more than $90 \%$. The first-line treatment is surgical excision, and although the debate continues as to whether a total thyroidectomy or thyroid lobectomy should be recommended, the treatment options that are chosen depend on patient factors, disease factors, and the decisions of the patient and treatment team [20]. Surgery is currently the only tested treatment option to cure papillary thyroid cancer. Most people can be cured by surgical removal of the thyroid gland. Once the diagnosis of papillary thyroid cancer has been made by fine needle aspiration biopsy, surgery is indicated in order to remove the tumor.

\section{Follicular Thyroid cancer}

Follicular thyroid cancer of the thyroid gland accounts for between $4 \%$ and $39 \%$ of all malignant thyroid tumors. Follicular carcinoma is more common in women who are affected over a broad age range [21].Cancer is basically a cell disease, characterized by a loss in the mechanisms which drive the proliferation and cellular differentiation [22]. The cells were cultured and the proliferation was assessed by cell counting using a haemocytometer after trypsin digestion [23].

Follicular thyroid carcinoma (FTC) is a well-differentiated tumor. In fact, FTC resembles the normal microscopic pattern of the thyroid. FTC originates in follicular cells and is the second most common cancer of the thyroid, after papillary carcinoma. Patients with differentiated thyroid cancer generally have a good prognosis and high cure rates; however, subgroups of patients exist who develop progressive disease with significant morbidity and mortality. The clinical outcome of patients with follicular thyroid cancer and distant metastases to define their presentation, impact of therapy and clinical outcome [24] .Genetic factors may also have a role in determining disease susceptibility but remain ill-defined. Histological, FTC is characterized by follicle formation and the absence of any papillary elements in the tumor. Differential diagnosis of a carcinoma can be difficult [25].

Tumors are rarely encountered in the nasal cavity. They comprise less than $1 \%$ of the nasal malignancies [26] Multivariate analysis was carried out using cause-specific survival rates. Independently important prognostic factors at initial treatment were age at diagnosis, extra thyroidal invasion, and degree of differentiation histological for papillary cancers; and extra thyroidal invasion, distant metastases, primary tumor size, nodal involvement, age at diagnosis, and postoperative status for follicular cancers [27].

Patients with follicular thyroid cancer, when first examined, usually have solitary thyroid nodules that are follicular neoplasms by aspiration cytology, and these nodules fail to regress in response to TSH-suppressive therapy. Frozen section rarely aids in management the preferred treatment for follicular neoplasm's is lobectomy followed by completion total thyroidectomy for histological proven carcinomas larger than $1.0 \mathrm{~cm}$. Total thyroidectomy allows use of thymoglobulin and radioiodine scanning to detect and treat metastatic disease. Complications of thyroidectomy were uncommon, and the mortality rate in treated patients was relatively low [28] Most appropriate individualized treatment planning approach all factors such as tumor and, tumor range of motion and patient tolerance toward the treatment technique need to be assessed [29].

\section{Medullary Thyroid cancer}

Unlike papillary and follicular thyroid cancers which arise from thyroid hormone producing cells, medullary cancer of the thyroid originates from the parafollicular cells (also called C cells) of the thyroid. Patients with clinically evident Medullary thyroid cancer should have a total extra capsular thyroidectomy with bilateral central neck dissection and therapeutic modified (functional) radical neck dissection when the primary tumor is greater than $1 \mathrm{~cm}$ and when the central neck nodes are positive [30]. Medullary thyroid cancer is a tumor of the thyroid $\mathrm{C}$ cells that occurs in sporadic and hereditary clinical settings. Genetic testing of at-risk individuals is available and has been applied to patient management. Plasma calcitonin levels are a 
very sensitive marker for the presence of disease. Surgery offers the best hope for cure and also is an effective modality for managing metastatic and recurrent disease [31]

The goal in managing patients who have MTC is to detect and surgically remove disease at an early stage. Tumor marker-based biochemical screening and DNA-based genetic screening have created the opportunity for effective prophylactic surgery in patients at risk for hereditary MTC. Complete surgical resection is critical for cure because cervical reoperation for persistent or recurrent disease benefits only select patients. With the advent of therapies that target the RETactivated pathways, new hope may be emerging for patients who have locally advanced or metastatic disease [32].The method of choice for screening the screening method presented here is capable of confirming the presence of the disease [33] multiplexed functional screening which is based on imaging multiple targets in the physiologic context of intact cells by extraction of multicolor fluorescence information [34].

It can be sporadic as well as hereditary. The histological classification nowadays is increasingly performed immune histological via calcitonin. Clinically the tumor ranges from the very small, but hormonally highly active form, to the aggressive, mostly undifferentiated form [35].Study confirms that MTC is not an infrequent finding among patients with thyroid nodules (nearly 1 in 250 patients). In addition, screening thyroid nodules with serum calcitonin measurement allows the diagnosis and treatment of MTC at an earlier stage, resulting in a better outcome compared with MTC not detected by serum calcitonin measurement. One of the reasons for this finding is that increasing the preoperative diagnostic accuracy of MTC prompts the surgeon to perform a more radical and possibly curative treatment. On this basis, routine measurement of basal serum calcitonin levels should be considered an integral part of the diagnostic evaluation of thyroid nodules [36].

\section{Anaplastic Thyroid cancer}

Anaplastic thyroid carcinoma is one of the most aggressive malignancies, with a poor prognosis. Although rare, representing only $2 \%$ of clinically recognized thyroid cancers, the overall median survival is limited to months. Most patients are elderly and seek treatment with a rapidly growing mass. Almost half the patients seek treatment with distant metastases, with as many as $75 \%$ developing distant disease during their illness. In most the patients, complete surgical resection is not possible. There are, however, a few patients with disease reported in the literature who has demonstrated long-term survival with aggressive multimodal therapy that included surgery, radiation, and chemotherapy [37].

Anaplastic thyroid carcinomas (ATCs) are highly aggressive, extremely lethal human cancers with poor therapeutic response. Chemokines are a super family of small cytokine-like proteins Some recent studies suggest that many of these pro-inflammatory Chemokines and their receptors are the products of proto-oncogene's or tumor suppressor pathways in many cancers. An understanding of this axis may enable researchers to develop targeted strategies for cancer [38]. Factors controlling tumor angiogenesis are varied and currently under investigation. Chemokines, which produced by both tumor cells and cells of tumor microenvironment are known with a role in tumor angiogenesis [39].

Although the majority of thyroid cancer patients presenting to our surgical endocrinology clinics present with and often curable disease, patients may rarely present with a history and physical findings suggestive of an Anaplastic thyroid cancer. The endocrine surgeon should recognize, diagnose, and treat this patient urgently and promptly. The clinical course and findings from two patients who presented to our endocrine surgery clinic recently are summarized below from the patients' clinical notes [40].

No effective treatment options currently are available to patients with Anaplastic thyroid cancer (ATC), resulting in high mortality rates. Epidermal growth factor (EGF) has been shown to play a role in the pathogenesis of many types of cancer, and its receptor (EGFR) provides an attractive target for molecular therapy [41]. Receptors are members of the six broad groups of oncogenic products that under finely tuned conditions play crucial biological roles in cell differentiation, organogenesis, development, tissues repair and apoptosis. These molecules have been conserved along the evolution and appear to be irreplaceable for the multiplicity and survival of organisms [42].

Targeting epidermal growth factor receptor (EGFR) is a promising approach to increasing radio sensitivity of head and neck cancers but treatment resistance remains an important clinical problem. Combining epidermal growth factor receptor inhibitors with radiation has been shown to be more effective than either treatment alone for head and neck carcinoma in multiple preclinical studies [43].

\section{Treatment for Thyroid cancer}

\section{Thyroid hormone replacement}

Many people have a thyroid gland that cannot make enough thyroid hormone for the body's needs. This is called Hypothyroidism and may be caused by a non-functioning thyroid gland (for example Hashimoto's disease), by destruction of thyroid gland by surgery or radiation treatment or by a non-functioning pituitary gland. Hypothyroidism is the most common reason for needing thyroid hormone replacement. Advanced verification of complete surgical and medical evaluations may minimize this event [44]. Radiation therapy is a complex radiotherapy technique which allows delivering radiation dose conforming to complex shaped target volumes and at the same time efficiently sparing the surrounding normal/healthy structure. Thus it is the treatment of choice for curative radiotherapy [45].

Hypothyroidism is an endocrine disorder affecting 1\%-10\% of the global population. Hypothyroidism is defined as an inadequate production of thyroid hormones by the thyroid gland and can cause numerous symptoms including fatigue, weakness, weight gain, and depression. Experimental studies and clinical data have demonstrated that thyroid-cell proliferation is dependent on thyroid-stimulating hormone (TSH), thereby providing the rationale for TSH suppression as a treatment for differentiated thyroid cancer. Several reports have shown that hormone-suppressive treatment with the L-enantiomer of tetraiodothyronine ( $\mathrm{L}_{-} \mathrm{T}_{4}$ ) benefits high-risk thyroid cancer patients by decreasing progression and recurrence rates, and cancer-related mortality [46].

\section{Radiotherapy}

Surgery is the most effective treatment for thyroid cancer; however, in some subsets of patients, the role of radiotherapy (RT) is important. The main indication for external-beam RT is incomplete surgery. When neoplastic tissue is left behind at operation, RT must be considered, but only if an experienced surgeon feels that everything that can be 
done has been done. Generally, in those patients, the neoplastic tissue involves the larynx, trachea, esophagus, blood vessels or mediastinum [47].

Radiotherapy is a common treatment for cancer, but failure is observed 30 to $40 \%$ of the time. It is more common in patients with abnormal p53. The phytochemical diferuloylmethane (curcumin) a naturally occurring flavanoid derived from the rhizome of Curcuma longa shows potential radio sensitizing effects. The expression of p53 and p53 target genes was examined using RNase protection assay and Western blot analysis. Cell cycle and apoptosis was evaluated by flow cytometry. Cell viability and colony formation was examined using MTT assay and clonogenic assay respectively [48] the p53 mutations observed in tumors represent the expression of such instability by allowing the accumulation of genetic alterations caused by multiple mechanisms [49].

The ionizing radiation technique was used in several countries mainly for the sterilization of health care [50].Radiation effects are mainly associated with the chemical changes but also depended on physical and physiological factors Dose rate, dose distribution, radiation quality, radiation type and exposure pattern are important physical parameters and also depends on physiological factors like growth phase, sensitivity [51].

\section{Radioactive iodine}

Radioactive iodine, given in a liquid form, is absorbed and concentrated by the thyroid gland. The treatment destroys thyroid tissue but does not harm other tissue in the body. Radioactive iodine (RAI) has been used in the treatment of thyroid malignancy for over 60 years. Several side effects of RAI administration are well known Xerostomia occurs in roughly $50 \%$ of patients receiving and is known to occur in a dose-dependent fashion.

Common ocular complications include chronic or recurrent conjunctivitis, dry eye syndrome, and xerophthalmia, which has been reported to occur in $23 \%$ of patients receiving radioiodine treatment for malignancy the use of radioactive iodine for the management of well-differentiated thyroid cancer, is greatly increasing [52]. Dry eye syndrome is a chronic lack of sufficient lubrication and moisture on the surface of the eye. Its consequences range from subtle but constant irritation to ocular inflammation of the anterior tissues of the eye [53]. Conjunctivitis is a local allergic condition centered mainly in the ocular area, although sometimes it is also associated with rhinitis. The disease ranges in severity from mild to severe forms [54].

Radioactive iodine is a form of iodine chemically identical to nonradioactive iodine. Therefore, the thyroid gland, which takes up iodine to make thyroid hormone, cannot distinguish between the two. Radioactive iodine remnant ablation destroys residual thyroid tissue after surgical resection of papillary or follicular thyroid cancer. Radioactive iodine ablation may be beneficial in decreasing recurrence of well-differentiated thyroid cancer [55]. There has been some controversy with regards to which preparation of radioactive iodine should be used [56].

Recent advances in diagnosis and treatment of cancer have led to an increase in cancer survival and hence, there is a greater emphasis on quality beside quantity of survival [57].

\section{Chemotherapy}

Chemotherapy involves the use of anticancer drugs to kill cancer cells. Some patients who receive chemotherapy for thyroid cancer may also need external radiation therapy. When it is used to treat people with thyroid cancer, chemotherapy may result in side effects such as an increased risk of infection, fatigue, hair loss, poor appetite, nausea, and vomiting. Post operative nausea and vomiting occurs in as many as $70 \%-80 \%$ of high risk surgical patients [58] these findings suggested that combination therapy with these agents may provide enhanced therapeutic response in cancer patients [59].

Cancer chemotherapy aim is to minimize the tumor burden at the end of the treatment period while maintaining a normal cell population above a lower level as a limit of toxicity [60]. Cancer is the state of cells marked by unregulated proliferation. There are several characteristic features attributed to its occurrence [61]. A growing interest in the use of adult stem cells for the treatment of several cancers has been developed over the last few years [62] the cancer stem cell theory has emerged as a paradigm shift in our understanding of cancer as a disease of stem cells. A small subset of cancer cells within the tumor mass has the exclusive capacity to divide and expand the CSC pool and to differentiate into non tumorigenic, more differentiated cancer cell lineages. The existence of these small subsets of cells is responsible for tumor recurrence and metastasis [63].

Several factor both inside and outside of the body may contribute to the development of many cancer types. Many human organs take several years to turn as malignant and have many causes [64] about $9 \%$ of the incident thyroid cancers could be attributed to prior head and neck irradiation, $4 \%$ to goiter, and $17 \%$ to thyroid nodular disease, leaving the etiology of most thyroid cancers yet to be explained [65]. Different chemotherapeutic agents and regimens are being tried to evaluate best outcomes [66]

Tumor cell invasion and metastasis is a compounding problem in cancer management, with therapeutic intervention of tumor invasion becoming recognized as an increasingly relevant clinical factor [67] Current research on diseases of the ear, nose, throat and related structures of the head and neck has experienced significant strides in areas including cancer, otology, rhinology and laryngology. Molecular diagnostics and advanced imaging modalities including positron emission tomography have facilitated diagnosis and patient outcomes. Collaborations between physicians and laboratory researchers working to identify key clinical issues and translating the biological insights into novel therapeutic approaches are crucial to significant progress in the field [68].

\section{Conclusion}

In conclusion, our study indicates that thyroid cancer in patients is rather advanced at initial examination and usually associated with thyroid nodules. Most often the first symptom of thyroid cancer is a nodule in the thyroid region of the neck .Radioiodine treatment, and thyroid suppressive therapy represent an effective combination of treatments for this disease and allow a good quality of life. Over the long term, for tumors that are not initially metastatic to distant sites, the above treatment is found to be effective and confers a distinct outcome advantage. This therapy reduces tumor recurrence and mortality sufficiently to offset the augmented risks incurred by delayed therapy, at the time of diagnosis, and tumors that are much larger than $1.5 \mathrm{~cm}$, or regionally metastatic. 


\section{References}

1. Dronca RS, Markovic SN, Holtan SG, Porrata LF (2011) Neuroendocrineimmune Crosstalk and Implications for Cancer Therapy. J Cell Sci Ther 2:102e.

2. Ying J, Quanjun W, Jinglan W, Songfeng W, Gang C, et al. (2008). Profiling of Phosphorylated Proteins in Human Fetal Liver. J Proteomics Bioinform 1: 437-457.

3. Goel R, Raju R, Maharudraiah J, Sameer Kumar GS, Ghosh K, et al. (2011) A Signaling Network of Thyroid-Stimulating Hormone. J Proteomics Bioinform 4: 238-241.

4. Tehrani FR, Tohidi M, Dovom MR, Azizi F (2011) A Population Based Study on the Association of Thyroid Status with Components of the Metabolic Syndrome. J Diabetes Metab 2:156.

5. Celik N, Andiran N (2011) A Case with Thyroid Agenesis and Primary Craniosynostosis: An Intriguing Coexistence. Pediatr Therapeut 1:104.

6. Sumer BD, Larrison D, Miles BA, Truelson JM, Ahn C, et al. (2011) Effect of Perioperative Hypothyroidism on Pharyngocutaneous Fistula Formation Following Total Laryngectomy. Otolaryngol 1:105.

7. Davies L, Welch HG (2006) Increasing incidence of thyroid cancer in the United States. JAMA 295: 2164-2167.

8. Ammer AG, Kelley LC, Hayes KE, Evans JV, Lopez-Skinner LA, et al. (2009) Saracatinib Impairs Head and Neck Squamous Cell Carcinoma Invasion by Disrupting Invadopodia Function. J Cancer Sci Ther 1: 052-061.

9. Pierre M, DeHertogh B, DeMeulder B, Bareke E, Depiereux S, et al. (2011) Enhanced Meta-analysis Highlights Genes Involved in Metastasis from Several Microarray Datasets. J Proteomics Bioinform 4: 036-043.

10. Thomas SM (2011) Otolaryngology Research: A New frontier in Head and Neck Cancer Genomics. Otolaryngology 1:102e.

11. Hamed RH, Elzahaf E (2011) Low Dose Weekly Paclitaxel Versus Low Dose Weekly Cisplatin with Concomitant Radiation in Locally Advanced Head and Neck Cancers. J Cancer Sci Ther 3: 166-171.

12. Mesía R, Vilajosana E, Lozano A, Esteller L, Silvia V (2009) Management of Cutaneous Toxicity and Radiation Dermatitis in Patients with Squamous Cancer of the Head and Neck Undergoing Concurrent Treatment with Cetuximab and Radiotherapy. J Cancer Sci Ther 1: 028- 033.

13. Bramley MD, Harrison BJ (1996) papillary microcarcinoma of the thyroid gland Br J Surg 83: 1674-1683.

14. Kakizaki H, Takahashi $\mathrm{Y}$, Ichinose A, Iwaki M (2011) Orbital lymphangioma: Considerable Shrinkage without Biopsy and Surgery. J Clinic Experiment Ophthalmol 2:137.

15. Song WZ, Wang Z, Li LW, Chen JH, Wang J (2010) Evaluation of Early Response to Neoadjuvant Chemotherapy in Breast Cancer Patients by 18F-FDG and 99mTc-HL91 Imaging. J Nucl Med Radiat Ther 1:102.

16. Motegi M, Tanaka S, Tada H, Sasaki T, Hashi A, et al. (2011) Comparison of Two Sampling Procedures for Diagnosing Endometrial Carcinoma and Hyperplasia: Outpatient Tissue Biopsy Versus Cytologic Examination. J Cytol Histol 2:118.

17. Sosa JA, Udelsman R (2006) papillary thyroid cancer. Surg Oncol Clin N Am 15: $585-601$

18. Brahmbhatt M, Yang S, Mahalingam M (2010) Proliferative Nodules in Congenital Nevi - A Histopathologic, Genetic and Immunohistochemical Reappraisal. J Clin Exp Dermatol Res 1:105

19. Ramanujan VK, Ren S, Park S, Farkas DL (2010) Non-invasive, Contrast enhanced Spectral Imaging of Breast Cancer Signatures in Preclinical Animal Models In vivo. J Cel Sci Therapy 1:102

20. Caron NR, Clark OH (2006) papillary thyroid cancer. Curr Treat Options Oncol 7: 309-319.

21. Thompson LD, Wieneke JA, Paal E, Frommelt RA, Adair CF (2001) A clinic pathologic study of minimally invasive follicular carcinoma of the thyroid gland with a review of the English literature. Cancer 91: 505-524.

22. Ferreira AK, Meneguelo R, Neto SC, Chierice GO, Maria DA (2011) Synthetic
Phosphoethanolamine Induces Apoptosis Through Caspase-3 Pathway by Decreasing Expression of Bax/Bad Protein and Changes Cell Cycle in Melanoma. J Cancer Sci Ther 3: 053-059.

23. Zhu W, Masaki T, Cheung AK, Kern SE (2009) In-vitro Release of Rapamycin from a Thermosensitive Polymer for the Inhibition of Vascular Smooth Muscle Cell Proliferation. J Bioequiv Availab 1: 003-012.

24. Vassilopoulousellin R, Delpassand E (1996) Follicular thyroid cancer. Int $J$ Oncol 8: 969-976.

25. Grebe SK, Hay ID (1995) Follicular thyroid cancer. Endocrinol Metab Clin North Am 24: 761-801.

26. Liu CY, Chang LC, Yang SW (2011) Metastatic Hepatocellular Carcinoma to the Nasal Cavity: A Case Report and Review of the Literature. J Cancer Sci Ther 3: 081-083.

27. Simpson WJ, McKinney SE, Carruthers JS, Gospodarowicz MK, Sutcliffe SB et.al (1987) Papillary and follicular thyroid cancer Prognostic factors in 1,578 patients. Am J Med 83: 479-488.

28. Emerick GT, Duh QY, Siperstein AE, Burrow GN, Clark OH (1993) Diagnosis treatment, and outcome of follicular thyroid carcinoma. Cancer 72: 3287-3295.

29. Mihaylov IB, Lerma FA, Moros EG (2010) Relation between Tumor Size and Range of Motion in IMRT Treatment Planning for Thoracic Lesions. J Cancer Sci Ther 2: 100-104

30. Kebebew E, Clark OH (2000) Medullary thyroid cancer. Curr Treat Options Oncol 1: 359-367.

31. Moley JF (1995) Medullary thyroid cancer. Surg Clin North Am 75: 405-420.

32. You YN, Lakhani V, Wells SA Jr, Moley JF (2006) Medullary thyroid cancer Surg Oncol Clin N Am 15: 639-660.

33. Hewavitharana AK, Shaw PN, Ng YK, Fuerst JN (2009) Simple Screening Method for Staurosporine in Bacterial Cultures using Liquid ChromatographyTandem Mass Spectrometry. J Bioanal Biomed 1: 001- 004.

34. Kozak K, Agrawal A, Machuy N, Csucs G (2009) Data Mining Techniques in High Content Screening: A Survey. J Comput Sci Syst Biol 2: 219-239.

35. Keminger K, Kokoschka R, Schmalzer E (1983) Medullary thyroid cancer. Wien Klin Wochenschr 95: 214-219.

36. Elisei R, Bottici V, Luchetti F, Di Coscio G, Romei C etal (2004) Impact of routine measurement of serum calcitonin on the diagnosis and outcome of medullary thyroid cancer: experience in 10,864 patients with nodular thyroid disorders. J Clin Endocrinol Metab 89: 163-168.

37. Pasieka JL (2003) Anaplastic thyroid cancer. Curr Opin Oncol 15: 78-83.

38. Singh RK, Sudhakar A, Lokeshwar BL (2010) Role of Chemokines and Chemokine Receptors in Prostate Cancer Development and Progression. J Cancer Sci Ther 2: 094-099.

39. Razmkhah M, Jaberipour M, Ghaderi A (2011) Chemokines and Chemokine Receptors Expression in the Adipose Derived Stem Cells (ASCs), Breas Tissues and in Peripheral Blood of Patients with Breast Cancer. J Carcinogene Mutagene 2:120

40. Dackiw AP(2010) Anaplastic thyroid cancer. Cancer Treat Res 153: 75-84.

41. Schiff BA, McMurphy AB, Jasser SA, Younes MN, Doan D (2004) Epiderma growth factor receptor (EGFR) is over expressed in anaplastic thyroid cancer, and the EGFR inhibitor gefitinib inhibits the growth of anaplastic thyroid cancer. Clin Cancer Res 10: 8594-8602.

42. Berlanga-Acosta J, Gavilondo-Cowley J, del Barco-Herrera DG, MartínMachado J, Guillen-Nieto G (2011) Epidermal Growth Factor (EGF) and Platelet- Derived Growth Factor (PDGF) as Tissue Healing Agents: Clarifying Concerns about their Possible Role in Malignant Transformation and Tumor Progression. J Carcinogene Mutagene 1:115.

43. Fu S, Rivera M, Ko EC, Sikora AG, Chen CT, et al (2011) Combined Inhibition of Epidermal Growth Factor Receptor and Cyclooxygenase-2 as a Nove Approach to Enhance Radiotherapy. J Cell Sci Ther S1:002.

44. Trentman TL, Mueller JT, Fassett SL, Dormer CL, Weinmeister KP (2010) Day 
Citation: Srilatha B, Hima Bindu A, Soumya D (2011) Epidemiology and Treatment for Thyroid Cancer. J Cancer Sci Ther S17. doi:10.4172/19485956.S17-011

of Surgery Cancellations in a Tertiary Care Hospital: A One Year Review. J Anesthe Clinic Res 1:109.

45. Kumar R, Sharma SD, Amols HI, Mayya YS, Kushwaha HS (2010) A Survey on the Quality Assurance Procedures Used in Intensity Modulated Radiation Therapy (IMRT) at Indian Hospitals. J Cancer Sci Ther 2: 166-170.

46. Biondi B, Filetti S, Schlumberger M (2005) Thyroid-hormone therapy and thyroid cancer: a reassessment. Nat Clin Pract Endocrinol Metab 1: 32-40.

47. Tubiana M, Haddad E, Schlumberger M, Hill C, Rougier P (1985) External radiotherapy in thyroid cancers. Cancer 55: 2062-2071.

48. Nayak BK, Krishnegowda NK, Galindo CA, Meltz ML, Swanson GP (2010) Synergistic Effect Between Curcumin (diferuloylmethane) and Radiation on Clonogenic Cell Death Independent of p53 in Prostate Cancer Cells. J Cancer Sci Ther 2: 171-181.

49. Abdullah S, Sameer S A, Dil-Afroze, Syeed N, Das BC, et al. (2010) P53- The Molecular Guardian Crashes in Gastric Adenocarcinomas - A Study in an Ethnic Kashmiri Population. J Carcinogene Mutagene 1:106.

50. Pedraza JM, Yusof N, Hilmy N (2011) A Review of the International Atomic Energy Agency (IAEA) Code of Practice for the Radiation Sterilisation of Tissue Allografts. J Cell Sci Ther 2:105.

51. Maruthi YA, Das NL, Hossain K, Sarma KSS, Rawat KP, et al. (2011) Advance Oxidation of Sewage Water, Reclamation and Hygienization by Radiation Technology: A Novel Approach. Hydrol Current Res 2:108.

52. Ramakrishnan VR, Durairaj VD, Kingdom TT (2011) Endoscopic Management of Acquired Nasolacrimal Duct Obstruction Secondary to Radioactive lodine Treatment for Thyroid Malignancy. J Aller Ther 2:110

53. Siu-Chun ND, Man-Kit YB, Edwin C, Wai-Nang CC (2011) Mycobacterial Chelonae Lacrimal Canaliculitis in A Patient After Punctal Plug Insertion for Post-LASIK Dry Eye. J Clinic Experiment Ophthalmol 2:182.

54. Baiza-Duran LM, González-Villegas AC, Contreras-Rubio Y, Juarez-Echenique JC, Vizzuett-Lopez IV, et al. (2010) Safety and Efficacy of Topical $0.1 \%$ And $0.05 \%$ Cyclosporine A in an Aqueous Solution in Steroid-Dependent Vernal Keratoconjunctivitis in a Population of Mexican Children. J Clinic Experiment Ophthalmol 1:115.

55. Sawka AM, Thephamongkhol K, Brouwers M,Thabane L,Browman G et.a (2004) Clinical review 170: A systematic review and metaanalysis of the effectiveness of radioactive iodine remnant ablation for well-differentiated thyroid cancer. J Clin Endocrinol Metab 89: 3668-3676.
56. Papanikolaou T, Islam T,Hashim A, Mariatos G (2011) Tolerability and Safety Profile of Povidone lodine in Pre-Operative Skin and Eye Disinfection Prior to Intraocular Surgery. J Clinic Experiment Ophthalmol 2:125.

57. Pakseresht S, Ingle GK, Garg S (2011) Quality of Life of Women with Breas Cancer at the Time of Diagnosis in New Delhi. J Cancer Sci Ther 3: 066- 069.

58. Bergese SD, Erminy N, Antor MA, Uribe AA, Puente EG (2011) Studying the Effectiveness of Triple Therapy with Palonosetron, Dexamethasone and Promethazine for Prevention of Post Operative Nausea and Vomiting in High Risk Patients Undergoing Neurological Surgery and General Anesthesia Internal Med: Open Access 1:101.

59. Shirode AB, Sylvester PW (2011) Mechanisms Mediating the Synergistic Anticancer Effects of Combined $\mathrm{y}$-Tocotrienol and Celecoxib Treatment. J Bioanal Biomed 3: 001-007.

60. Murray JM (1990) Optimal control for a cancer chemotherapy problem with general growth and loss functions. Math Biosci 98: 273-287.

61. Nair A (2010) Amplified Hypoxia Induced Tumor-Cell Death In vitro. J Carcinogene Mutagene 1:109.

62. Minguell JJ, Pereira A, Bartholomew P and Lasala GP (2011) The Intratheca Infusion of Mesenchymal Stem Cells into Healthy Rabbits is Safe and Devoid of Neurological or Clinical Complications. J Stem Cell Res Ther 2:104.

63. Kurioka D, Takagi A, Yoneda M, Hirokawa Y, Shiraishi T, et al. (2011) Multicellular Spheroid Culture Models: Applications in prostate Cancer Research and Therapeutics. J Cancer Sci Ther 3: 060-065.

64. Singh RK, Sudhakar A, Lokeshwar BL (2011) From Normal Cells to Malignancy Distinct Role of Pro-inflammatory Factors and Cellular Redox Mechanisms. J Cancer Sci Ther 3: 070-075.

65. Ron E, Kleinerman RA, Boice JD Jr, LiVolsi VA, Flannery JT (1987) A population-based case-control study of thyroid cancer. J Natl Cancer Inst 79 $1-12$.

66. Gayed IW, Wahba H, Wan D, Joseph U, Murthy R (2010) Effect of Y-90 SIRSpheres Therapy for Multiple Liver Metastases in a Variety of Tumors. J Cancer Sci Ther 2: 043-046.

67. Ammer AG, Kelley LC, Hayes KE, Evans JV, Lopez-Skinner LA, et al. (2009) Saracatinib Impairs Head and Neck Squamous Cell Carcinoma Invasion by Disrupting Invadopodia Function. J Cancer Sci Ther 1: 052-061.

68. Thomas SM (2011) Otolaryngology Research: A New frontier in Head and Neck Cancer Genomics. Otolaryngology 1:102e. 